\title{
De GADES A HisPaLIS, dos PUERTOS ATLÁNTICOS EN LA conformación de la Provincia BaEtica*
}

\author{
From Gades to Hispalis, two atlantic ports in the conformation \\ of the provincia Baetica
}

\author{
Javier Bermejo Meléndez \\ Francisco Marfil VázQuez \\ Juan Manuel Campos Carrasco \\ Universidad de Huelva
}

Recibido: 08/01/2018

Revisado: 13/04/2018
Aceptado: 31/05/2018

Publicado: 29/06/2018

\section{RESUMEN}

En este trabajo se realiza un análisis comparativo entre el que fue el principal puerto meridional de la Península Ibérica antes de la llegada de Roma-Gades- y el que asumirá esa condición predominante tras la conformación de la Provincia Baetica -Hispalis- gracias al impulso que le proporcionará su desarrollo como puerto annonario y puerta de entrada a la provincia tras las reformas augusteas. En la segunda mitad del s. I a.C. y especialmente a inicios del principado, ambas ciudades tendrán un importante crecimiento urbanístico, transformación y aumento de espacios productivos y crecimiento de sectores económicos. Sin embargo en el devenir del s. I d.C. el puerto hispalense tendrá un importante despegue como núcleo portuario bético, confirmado por indicadores económicos así como por la presencia de importantes magistrados $\mathrm{y}$ funcionarios imperiales.

\section{Palabras Clave}

Conventus; Hispalis; Gades; Portus; Annona.

\section{Abstract}

This work made a comparative analysis between which was the main southern port of the Iberian Peninsula before the arrival of Rome-Gades- and which will assume that predominant condition after the conformation of the Provincia Baetica -Hispalis- thank of the impulse that will provide it the development as an annonary port and gateway to the province after the Augustan reforms. In the second half of the Ist century b.C. and specially at the beginning of the principality, both cities will seen an important urban development, transformation and increase of productive spaces and development of economic sectors. However, in the future of the Ist century a.C. the port of Seville will see an important takeoff as a Betic port core, confirmed by economic indicators as well as by the presence of important magistrates and imperial officials.

\section{KEY WORDS}

Conventus; Hispalis; Gades; Portus; Annona.

"El presente trabajo se enmarca dentro de las actividades de los proyectos de investigación "Del Atlántico al Tirreno. Los puertos atlánticos béticos y lusitanos y su relación comercial con Ostia Antica” (DeAtlantir) (HAR2014-58326-P) perteneciente al Plan Nacional de I+D+I y así como su segunda fase "Del Atlántico al Tirreno (2 FASE), Los puertos Hispanos y su relación comercial con Ostia Antica (HAR2017-89154-P)" "Ciudades Romanas de la Bética. CORPVS VRBIVM BAETICARVM”(CVB) (HUM 2062) correspondiente a la convocatoria de Proyectos de Excelencia del Plan Andaluz de Investigación.

javier.bermejo@dhis1.uhu.es 
La PROVINCIA BAETICA y SU REORganización AuGUSTEA.

A mediados del s. I a. C. la provincia Bética se define como uno de los territorios de mayor interés para la administración de Roma, este territorio en época tardorrepublicana ofrecía una situación idónea, con un gran potencial económico (Chic García, 2017), una vez conseguida la pacificación total con la eliminación de los últimos seguidores pompeyanos y habiéndose controlado sus actos de bandidaje. Recientes análisis de conjunto (Fornell Muñoz, 2015; Guzmán Armario, 2015; Lechuga et alii, 2015; Pastor Muñoz, 2015; Campos y Bermejo, 2015) han puesto de relieve la importancia de las medidas de Augusto en el proceso de creación y transformación de la Bética, la cual, ya en tiempos de César, destacará por su peso geopolítico y sus importantes recursos mineros y agrícolas, vitales para la acuñación de moneda y la annona- (Guzmán Armario, 2015, 41-42), esto es, buena parte del éxito de la provincia en los siglos inmediatamente posteriores se debe a su diversificación económica (Gozalbes Cravioto, 1995, 229).

La creación de la Provincia Baetica se fecha según Dión Casio (LIII, 12) en el 27 a.C., pero la fundación de Augusta Emerita y los viajes de Augusto a Hispania hacen que se dude entre si este acontecimiento se produjo durante el segundo viaje (Oscáriz Gil, 2009, 333) o el tercero (Ureña Alonso, 2001, 211; Abascal Palazón, 2006, 75). Sea como fuere, se creaba la única provincia senatorial de Hispania marcada por un alto grado de pacificación y una buena adaptación a la cultura romana. El modelo de organización que desarrolla Augusto perseguía un fin claro, hacer del territorio un organismo lo más eficiente posible, lo que suponía llevar a cabo labores de deducciones, divisiones agrarias $y$ fundaciones ex novo para un mayor control territorial mediante las políticas municipalizadoras y promociones jurídicas de sus ciudades. César inició un proceso que tuvo su eclosión en época augustea, la especialización productora de las villae, ya fuera en zonas favorables para el cultivo, la ganadería o la explotación de los esteros y riberas, constatándose salinas incluso en zonas del interior como Astigi (Chic García, 1997, 59 y ss.). El conjunto de procesos administrativos ligados a la ordenación del imperio por Augusto inciden en una misma dirección, desde la constitución de la nueva provincia, a los controles y censos de cara a los tributos; la posible articulación de los conventus, o la restructura- ción de las fronteras provinciales, todo ello con el trasfondo de la implantación del sistema fundus / pagus al unir los aspectos fiscales, censales y catastrales (Wulff, 1996, 48) (Fig. 1).

Los sucesores julio-claudios mantuvieron las políticas territoriales, coincidiendo con una etapa de esplendor en la Baetica contrario al progresivo proceso de endeudamiento que vivía el Imperio debido al aumento del gasto militar, que tuvo como consecuencia más directa una serie de políticas de austeridad en el reinado de Tiberio. La prosperidad bética vivida durante éste, marca una etapa en la que comienza a independizarse de los productos itálicos tras el período de adaptación de los colonos augusteos, produciéndose un cambio paulatino que la convierte en una región principalmente exportadora. El potencial agrícola, ganadero, pesquero y minero la mantienen relativamente al margen de la época de carestía que vivía el Imperio, siendo una etapa de prosperidad y expansión mercantil y urbana (Chic García, 1991).

Es pues que tras su fundación, la Bética, desgajada de la anterior Ulterior, surge como un referente de territorio romanizado y plenamente integrado en el engranaje económico del Imperio. A pesar de algunos interrogantes que rodean a ciertos aspectos, como es la propia fecha de su creación, o los límites de la misma, a través de los autores del momento tenemos una imagen bastante clara sobre cómo era la provincia en la Antigüedad. Así Estrabón definió el territorio regado por el Baetis como la región más rica de la oikoumene, tanto por sus recursos terrestres como marítimos (Estr. III, 1, 6), condición de sobra conocida tanto por la administración romana como por aquellos pueblos que con anterioridad habían establecido contacto con este territorio. En el capítulo segundo (Estr. III, 2), se hace un especial hincapié en las posibilidades de la Bética como centro exportador por sus condiciones naturales, la navegabilidad de sus ríos y por la adaptación que sus habitantes habían hecho a la cultura romana habiendo, incluso, "olvidado su propio idioma y haciéndose latinos” (Estr. III, 2, 15). Estas riquezas hacen alusión a la gran fertilidad de sus tierras, con un clima y unos suelos idóneos para el cultivo que la convirtieron en uno de los principales aportadores de trigo, aceite y vino de todo el Imperio (Plácido Suárez, 1987-1988; Chic García, 2001, 674 y ss.; 2010-2011; García Vargas, 2004; 2010; 2012b; García y Bernal, 2009). A estos recursos hay que sumar las grandes concentraciones de minerales 
de Sierra Morena y la faja pirítica del suroeste, una industria que hasta el momento había sido objeto de leyendas y relatos míticos dada su elevada producción y que tuvieron una importancia capital en la administración y la política económica y monetaria durante todo el período de ocupación romana, especialmente tras el establecimiento del monopolio imperial sobre la misma (Pérez Macías, 2002).

Además de los recursos con los que contaba, la ubicación de sus dos arterias principales -Guadiana y Guadalquivir- permitía la conexión de las rutas comerciales marítimas con el interior, dejando a su paso una larga lista de puertos y ciudades que nacían en sus riberas como consecuencia del trasiego comercial. La posibilidad de remontar el Guadalquivir hasta la capital, independientemente del calado de las embarcaciones, suponía una ventaja con respecto al costoso transporte por tierra. Si a esto le añadimos que todas las capitales conventuales están situadas en el cauce del Baetis, es fácil identificarlo como un elemento crucial dentro de los circuitos comerciales, de abastecimiento y control del territorio. Para G. Chic (1997, 20 y ss.) esta situación, con las cabezas conventuales ubicadas en torno al Guadalquivir y a la vía Augusta obedecía a una or- denación territorial al servicio de una estructura racional del valle del Betis. En ella, los núcleos privilegiados se encargaban de extender la romanización como centros de control económico y territorial de las civitates, aquellas que llenaban las arcas del Estado con el pago de sus impuestos y los beneficios del comercio. Esta organización territorial generó en la provincia una enorme riqueza, promovida por la creación de infraestructuras portuarias y caminos, que eran un potente foco de atracción para la oligarquía indígena, viéndose seducidos por la esperanza de una rápida promoción política y económica; no es de extrañar, por tanto, que el primer emperador nacido fuera de la península itálica fuera bético; en síntesis con Augusto se desarrolla todo un programa tendente a la organización racional de la provincia desde el punto de vista político, administrativo y de la propiedad (Guzmán Armario, 2015, 42-49).

Todos estos puntos favorables y dinamizadores de la Baetica, supusieron la rápida ascensión jurídica de las ciudades durante los primeros años del imperio, amparadas además por el patronazgo de la casa imperial en la figura del propio princeps o de los miembros de la domus augusta como ejem-

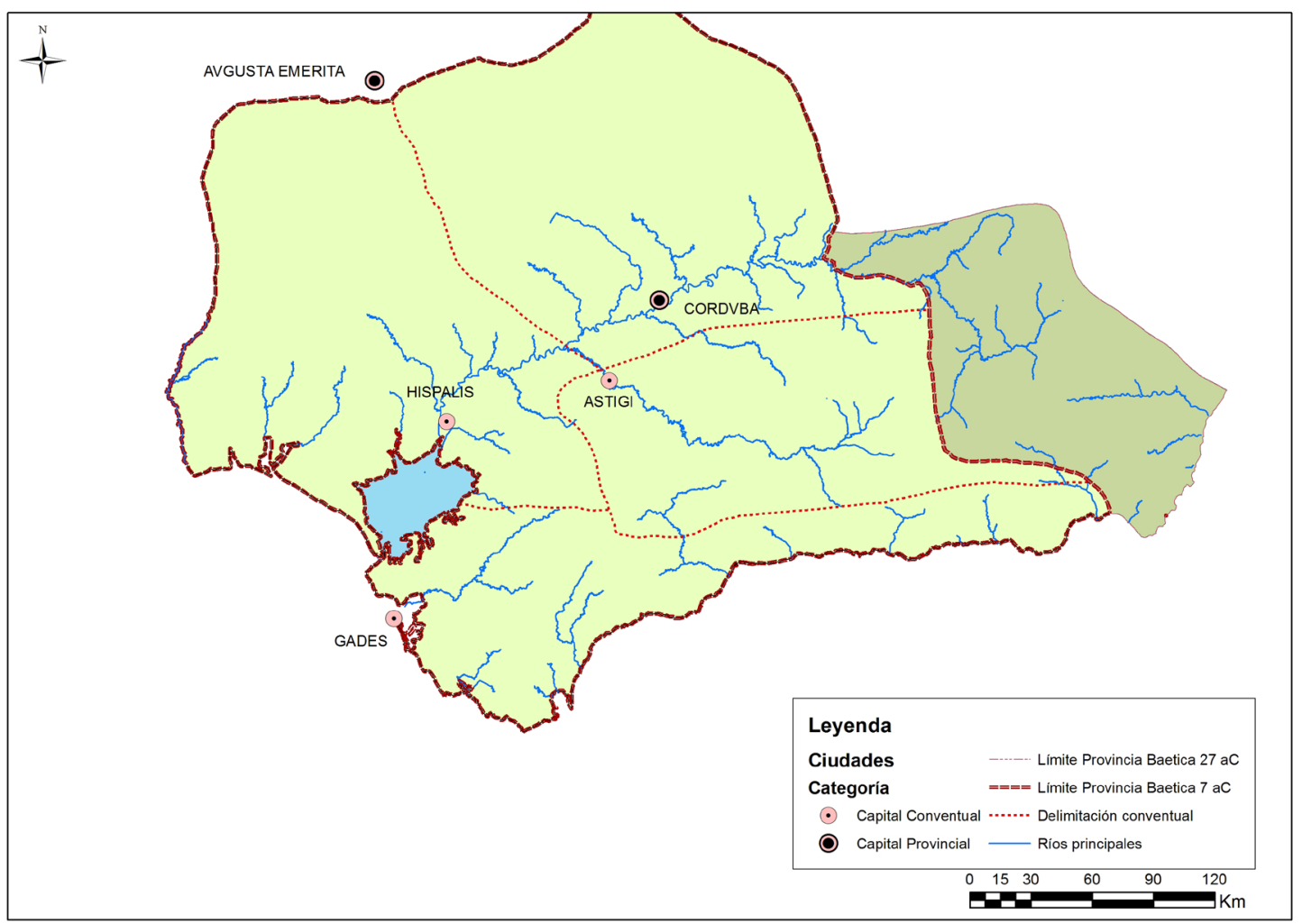

Fig. 1. Mapa de la Bética con indicación de sus unidades administrativas conventuales. 
plifican los testimonios de Ulia Fidenta, Gades o Italica (Melchor Gil, 2014, 261 y ss.) lo que explica la multiplicación de altares dedicados a Augusto durante la etapa altoimperial con el título de pater patriae así como a príncipes de su domus (Abascal Palazón, 2006, 75).

Del Portus Gaditanus al Hispalensis. el surGIMIENTO DE UN NUEVO EMPORIO COMERCIAL PROVINCIAL.

Enmarcados en estos procesos históricos de creación de la Provincia Baetica, ya en sus primeros momentos, se empieza a producir un importante ascenso de Hispalis como nodo comercial, debido a un progresivo traslado del epicentro económico desde el área del puerto de Gades, principal puerto de la Bética en época republicana, hacia el interior. Síntomas de este proceso de ascenso económico se advierten, entre otros, en la evolución del urbanismo de la Colonia Romula; como fiel reflejo de los procesos económicos, políticos y sociales que acaecían en esta ciudad.

Para Gades y su hinterland portuario-marítimo más próximo, existe una profusa producción científica acerca de la envergadura y el peso que llegó a alcanzar antes de la llegada de Roma y en los momentos inmediatamente posteriores, con especial incidencia en su importante industria haliéutica (entre otros: Ponsich, 1968; Ruiz Mata, 1986; 1987; Perdigones et alii, 1990; García y Chaves, 1991; Ruiz y Pérez, 1995; Niveau y Ruiz, 2000; Bernal y Lagóstena, 2004; Sáez Romero, 2008; Sáez y Díaz, 2014; Niveau de Villedary, 2015; Sáez et alii, 2017).

Sobre el poblamiento prerromano de las islas se han propuesto numerosas hipótesis, pero los testimonios arqueológicos llevan a plantear un asentamiento insular en el actual Cádiz en las inmediaciones del teatro cómico, calle Ancha, que parece iniciarse en torno al s. IX a.C.; sobre la base de un patrón de asentamiento disgregado en el entorno insular de la Bahía y en tierra firme con varios núcleos de habitación principales desde época arcaica (Niveau de Villedary, 2014, 486). La pujanza de su puerto le otorgó una posición privilegiada actuando como foco de atracción poblacional, aunque no será hasta finalizar la guerra civil y recibir rango de ciudad de derecho romano -49 a.C.-, cuando se abra la posibilidad a una reforma urbanística a gran escala.

La propia ciudad se verá transformada, por el importante papel que ejercía como controladora de las rutas atlánticas, al ser favorecida en el contexto bélico de las guerras civiles al prestar su apoyo a César en defensa de sus intereses marítimos y comerciales tanto atlánticos como norte africanos; gracias a este posicionamiento se producirá un importante despegue en todos los aspectos en las décadas finales del s. I a.C. (Guzmán Armario, 2015, 48). No debemos olvidar la importancia previa de este puerto en el mediodía peninsular, el cual no dudará en su cambio de orientación y proceso de romanización de cara a mantener sus negocios e influencia, en palabra de G. Chic, ser independientes había dejado de ser rentable para los gaditanos, Roma necesitaba del control de las rutas oceánicas que ejercía Gades, pero también ésta necesitaba insertarse en el marco de una economía mediterránea cada vez más directamente controlada por Roma (Chic García, 2017, 840 y ss.).

Ya desde el s. V a.C. el entorno de Gadir desarrolló una producción cerámica y salazonera industrial de primer orden que llevó a las producciones gaditanas a los puntos más extremos del Mediterráneo insertas en todas las rutas conocidas, lo que conformó un emporio comercial que mantendrá su pujanza hasta la aparición de Roma (Díaz et alii, 2003, 132). Entre el siglo III y la segunda Guerra Púnica, las necesidades del ejército cartaginés y la intervención armada en la Península Ibérica fue aprovechada por los bárquidas para dar salida a sus salazones (Sáez et alii, 2004, 56), una práctica que se repetirá durante la etapa altoimperial durante los conflictos en el limes renano-danubiano y en la conquista de las islas británicas hacia donde llegan los productos gaditanos. No obstante, el proceso de entrada en la órbita de Roma llevará parejo importantes cambios productivos en el traspaís agrícola peninsular gaditano, lo que cristalizará con el modelo de poblamiento basado en la villa (Díaz et alii, 2003,124-126). Así pues, en la transición y adaptación del modus vivendi romano, se generará un nuevo patrón de ocupación y aprovechamiento en el interior, tierra adentro, con un importante área portuaria redistribuidora en donde los productos salazoneros - con sus industrias auxiliares alfareras - junto con la producción agraria representen un engranaje industrial de corte exportador (Sáez y Díaz, 2012, 260, 261).

Será en el cambio entre el II y el I a.C. cuando el número de saladeros empiece a descender en pos de un sistema de explotación más intensivo, aumentando el número de figlinae en el nuevo siste- 


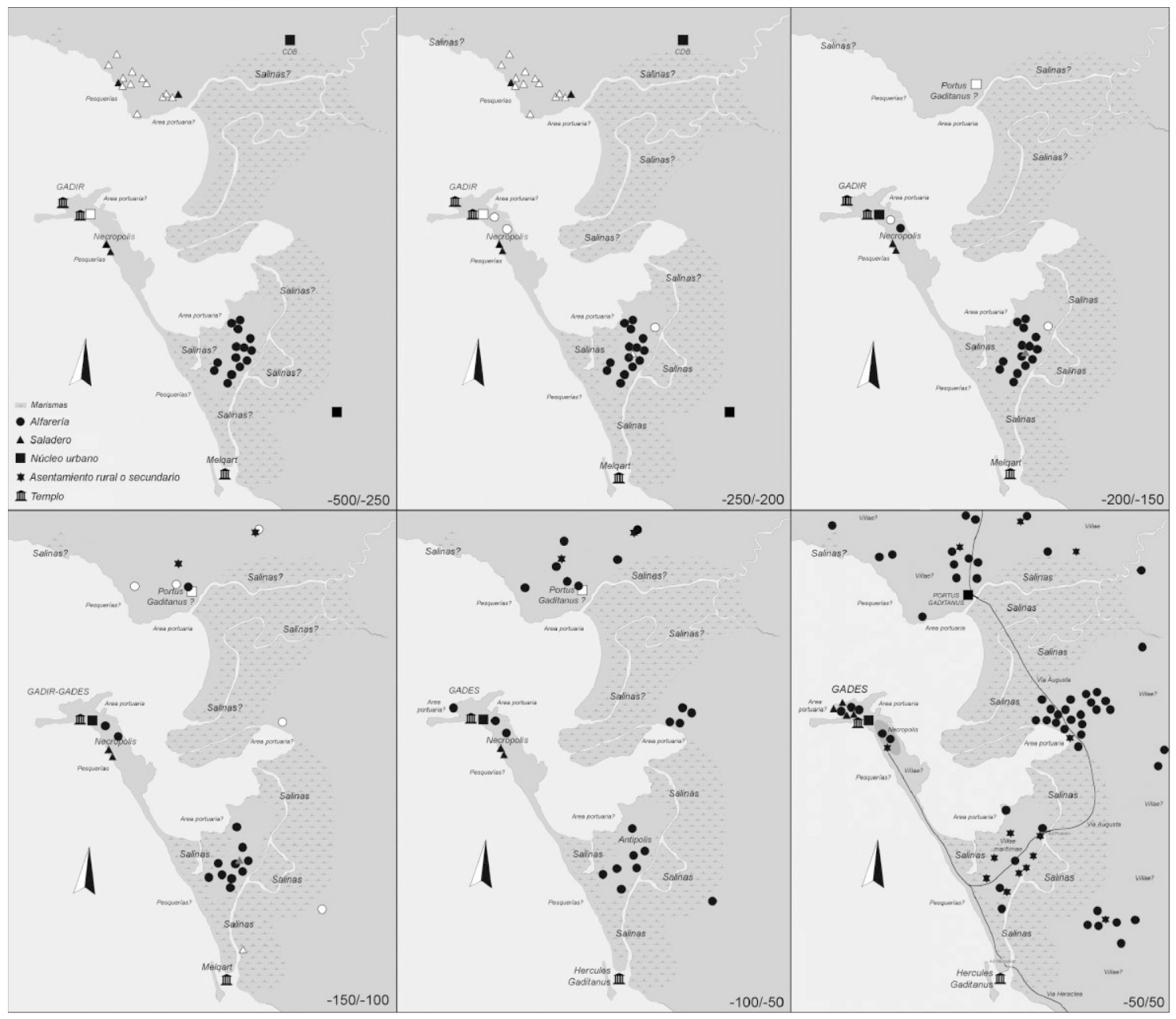

Fig. 2. Propuesta de evolución del sistema de poblamiento de la bahía gaditana entre los siglos VI y I a.C., con indicación de las principales áreas funcionales de Gadir-Gades (sobre planimetría actual) (Sáez Romero, 2010, Fig. 4, 902).

ma de explotación ${ }^{1}$ de las villae, abandonando las formas púnicas del último tercio del I a.C., nuevos centros alfareros que salpicarán la bahía bajo los parámetros de producción esclavistas romano. No es de extrañar que a finales del I a.C. aumentaran las exportaciones de salazones y productos vinícolas de manera significativa, siendo el puerto principal de la escala hacia el Atlántico y Britania, en el que

1 La naturaleza del régimen de explotacióncomercialización en lo que respecta a la Bahía de Cádiz supone un debate que abarca desde la llegada fenicia hasta la propia ocupación romana. Las teorías oscilan entre una producción controlada por la oligarquía o una economía de iniciativa privada que no estaba sujeta a ningún tipo de regulación (para consultar la síntesis sobre la problemática del régimen de explotación-comercialización del entrono de la Bahía de Cádiz vid. Sáez Romero, 2010, 903 y ss.). ahora se cuenta con una importante obra de adecuación para dar salida y atender correctamente su papel comercial de primer orden; el portus gaditanus (Chic García, 1979, 11-13; Montero et alii, 2004, 422-425; Sáez Romero, 2010, 898-903; Sáez y Díaz, 2012, 292-294). En este proceso de nuevo G. Chic indica cómo la antigua talasocracia gaditana debió adaptarse a los nuevos condicionantes sociales, al asemejarse a la nobilitas romana y su poder fundiario, de lo que se produjo una progresiva adaptación económica en la adquisición de tierras de labor (Chic García, 2017, 842) (Fig. 2).

El crecimiento de la maquinaria estatal de la annona, especialmente durante la dinastía flavia y la puesta en marcha de las medidas desarrolladas por Trajano en lo tocante al comercio marítimo, hará que Gades, así como el resto de puertos bé- 
ticos, vean un descenso de su producción, siendo los productos ligados a la oficialidad de la annona los únicos que mantenían sus niveles anteriores. En este sentido los comerciantes y productores gadiritas se apartaron de las rutas oficiales y explotaron las necesidades alimenticias de los ejércitos en el limes renano-danubiano y el nuevo mercado británico. Las políticas de Claudio, Nerón y Vespasiano permitieron a los navegantes gaditanos ligarse al sistema annonario aportando naves a cambio de exenciones fiscales, aunque esta casuística no fue suficiente para permitir a los pequeños y medianos comerciantes fletar barcos sin formar asociaciones (García Vargas, 1998, 233-237).

La dinastía severiana y sus medidas intervencionistas en la annona como castigo a los partidarios de Clodio Albino en la guerra del 193, fueron negativas para la ciudad, a pesar de ello, los mercados occidentales seguirán recibiendo ánforas salsarias béticas, aunque se convertirá en estancamiento en el principado de Antonino Pio y en recesión con Marco Aurelio, reflejándose en la desaparición del culto imperial por parte privada en las ciudades (Etienne, 1974, 495). La decadencia de salazones de la costa bética y la crisis de los saladeros obligó a los habitantes del litoral a diversificar, explotando una mayor cantidad de ánforas olearias y vinarias en los primeros tiempos de los Severos. Los productos de la costa bética entre el III y IV solo aparecerá ligada al comercio privado y del ejercito, así como a ciertas partes de la administración o la plebe frumentaria (García Vargas, 1998, 241-248). La escasez de monedas en las necrópolis gaditanas desde finales del II y una reducción de las importaciones cerámicas constatan un descenso demográfico en Gades, aunque con Constantino se ha evidenciado una cierta recuperación, la ausencia de un representante de la ciudad en el primer Concilio de Elvira - principios del s. IV - confirma la falta de entidad de Gades (Villaverde Vega, 1997, 411-413).

Ya centrados en la propia Gades, sobre el urbanismo de épocas republicana y altoimperial se presentan numerosas lagunas debido al condicionante insular del asentamiento gaditano, viéndose fuertemente limitado por la costa; la falta de análisis arqueológico de conjunto plantea la necesidad de realizar estudios alternativos que aporten conocimiento acerca del puerto de Cádiz, así como para verificar la hipótesis de una tupida red de embarcaderos y puertos distribuidos por el archipiélago y la desembocadura del Guadalquivir (Bernal Casasola, 2012, 225).
Los estudios de síntesis sobre la Cádiz romana y su estructura urbana permiten intuir un importante desarrollo urbanístico en el contexto de la segunda mitad del s. I a.C. con una importante proyección posterior (Ventura Villanueva, 2008; Bernal y Lara, 2012) ${ }^{2}$, ideas que cuentan con el respaldo de las fuentes clásicas; Estrabón (III, 5, 3) indica que a mediados del I a.C. en la ciudad se lleva a cabo una remodelación urbanística por parte de Balbo el Menor, construyendo una ciudad nueva junto a la anterior en el actual barrio de Santa María, una zona hasta entonces periurbana y que ahora acogería el foro (Niveau de Villedary, 2014, 494-495). Cicerón por su parte $(A d A t t, 12,2,1)$, comenta que en el 46 a.C., Balbo el Mayor se encontraba en Gades realizando actividades constructivas, una tarea que fue continuada por su sobrino durante su magistratura como $I V v i r$ entre el 44 y 43 . Síntoma de esta nueva imagen urbana podría haber quedado retratada en las acuñaciones (19-14 a. C.) que muestran un templo tetrástilo con un clípeo decorando el frontón, siendo ésta la imagen que la ciudad quería transmitir de ella misma al resto del imperio (Chaves et alii, 1999). Se trata de un momento en el cual ya gozaba del derecho romano y, como tal, se presupone una serie de cambios urbanísticos que adaptaban la ciudad al modelo y a la administración romana, unas remodelaciones que se producirían durante el cambio de Era experimentando una fase monumentalizadora.

Así pues a día de hoy desde el punto de vista arqueológico, Gades se muestra con un rico e importante potencial arqueológico de cara a su análisis que permite establecer importantes áreas suburbanas con un marcado carácter polifuncional, representadas por necrópolis y barrios industriales (Expósito Álvarez, 2004, 162 y ss.; Bernal Casasola, 2008, 286); ludi como el teatro y el más que probable anfiteatro en las inmediaciones de Puerta Tierra que confieren a la ciudad su aspecto más monumental (Lapeña Marchena, 1996; Bernal y Arévalo, 2011); áreas domésticos residenciales en las inmediaciones del barrio de Santa María y los restos de la Casa del Obispo (Gener y Pajuelo, 2002); y todo un importante área portuaria a lo largo del antiguo

2 Para el urbanismo gaditano próximamente se contará con la publicación de los datos aportados por la tesis doctoral, recientemente defendida en la Universidad de Cádiz por la Dra. M. Lara, titulada Urbs Iulia Gaditana. El urbanismo de Gades a través del registro arqueológico. Análisis y propuesta interpretativa. 
canal Bahía-Caleta, ahora ya parcialmente cegado, que permitió la instalación de un puerto interior y otro exterior en torno al cual se dispuso un importante barrio industrial urbano localizado en áreas de la zona de la playa de la Caleta o los restos del antiguo teatro Andalucía (Expósito Álvarez, 2004, 89, 123) (Fig. 3).

La amplia bibliografía existente para Hispalis y su urbanismo permite un amplio conocimiento de la ciudad y su evolución en el tránsito hacia el alto imperio, momento en el que se posicionará como el principal puerto bético. Las distintas hipótesis de trabajo y planteamientos sobre sus diversos conjuntos monumentales públicos forenses marcaron buena parte de la historiografía del yacimiento desde la segunda mitad del s. XX (Collantes de Terán, 1977; Blanco Freijeiro, 1979; 1992; Campos y González, 1987; Campos Carrasco, 1990; 1993; González Fer- nández, 1993). El amplio elenco de datos urbanos obtenidos en el transcurso de estas décadas permitió los primeros estudios de conjunto, donde destaca el primer trabajo de arqueología urbana de Sevilla - Proyecto Hispalis - que marcó el desarrollo de la investigación posterior (Campos Carrasco, 1986).

Lejos de continuar esa proyección y salvo algunas aportaciones aisladas (Rodríguez Temiño, 1991), habría que esperar un largo periodo para volver a encontrar una obra de conjunto sobre el urbanismo hispalense y su significación como puerto bético aunque sin aportar ninguna interpretación distinta (Beltrán et alii, 2005) las cuales se han implementado en los últimos tiempos, casi tres décadas después, con obras de síntesis, análisis y digitalizado de las evidencias arqueológicas de época romana en Sevilla, permitiendo un mejor manejo de los datos y facilitando la comprensión general y diacrónica

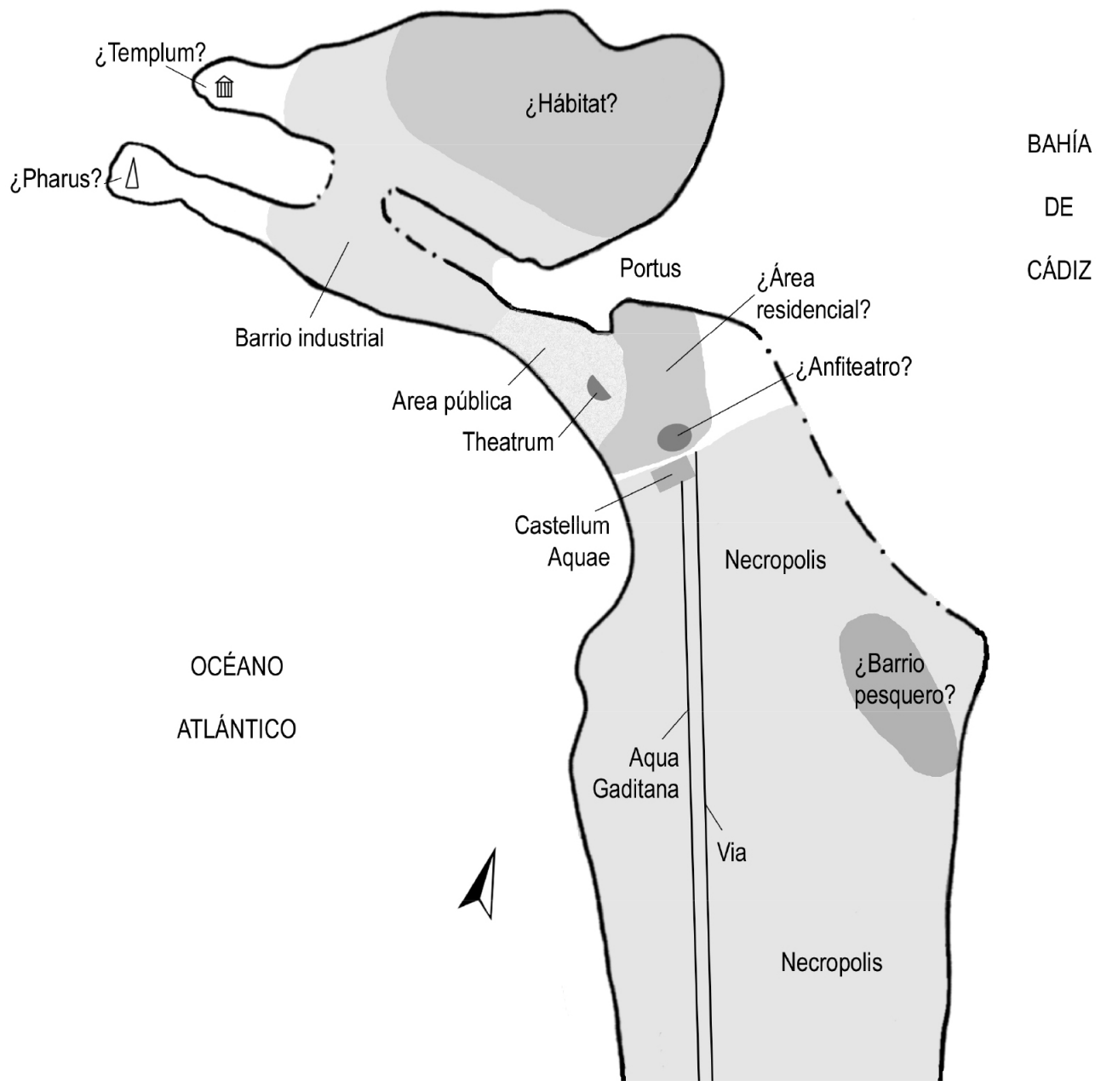

Fig. 3. Áreas funcionales y edificios identificados del urbanismo de Gades, propuesta de Arteaga et alii, 2001; 2004 sobre la paleotopografía (Bernal Casasola, 2008, Fig. 8). 
de la ciudad (González Acuña, 2010; 2011a; 2012; Cabrera Tejedor, 2014; 2016; García et alii, 2017).

Durante los últimos decenios del I a.C. y los primeros de nuestra Era, Hispalis será la ciudad bética que presente el mayor crecimiento, hasta el punto de que el propio César recoge la magnitud de sus astilleros indicando que rivalizan con los gaditanos (Bell. Civ. 2, 18, 1), además de mencionar la existencia de un gran recinto amurallado y un foro ( $i b i$ dem, 2, 20). La pronta asimilación de las infraestructuras civiles romanas, así como la expansión urbanística evidencian una sociedad basada en una potente oligarquía cada vez más insertas en el modo de vida romano, amén de una creciente demanda de productos por parte de una población creciente. En cuanto al urbanismo general se refiere (Fig. 4), la ciudad experimenta una gran expansión vinculada a los espacios fluviales y su evolución geomorfológica, con espacios de producción industrial que se extienden hasta los márgenes del Guadalquivir, ocupando toda la zona disponible al sur y dilatándola hacia el norte, aumentando necesariamente el perímetro amurallado (García et alii, 2017).

La ribera es ocupada por múltiples embarcaderos, industrias salazoneras y los necesarios horrea, además se incrementan los espacios sacros dedicados a divinidades vinculadas con el comercio y el mundo portuario como muestran las evidencias asociadas a un Iseum en la zona de expansión sur, así como de toda una serie de posibles sacella y sedes colegiales donde destacan los sectores de la ribera (González Acuña, 2010; 2012, 867-872).

Por su parte, la epigrafía ${ }^{3}$ revela una presencia notable de altos funcionarios imperiales, funcionarios de la annona, de todo un conjunto de subalter-

3 A. Blanco (1979; 1992), J.M. Campos (Campos y González, 1987; Campos Carrasco, 1990; 1993) y J. González (1993) proponen la existencia de un foro de las corporaciones como epicentro de la actividad comercial hispalense. Esta hipótesis se basa en los hallazgos epigráficos honoríficos de personas relacionadas con el comercio y la navegación en la zona de la actual Catedral, y las termas bajo el Palacio Arzobispal, además del tremendo dinamismo alcanzado en este momento, en el cruce del Tagarete y el brazo principal del Guadalquivir. Otros autores (Rodríguez Temiño, 1991; Tabales Rodríguez, 2001; Beltrán et alii, 2005; González Acuña, 2008; 2011a, b; 2012), matizan la naturaleza de este espacio, planteando que fuera la sede de un colegio de olearios o una statio olearium como complejo de un carácter más amplio, incluyendo funciones fiscales, administrativas, comerciales, etc. más allá de una sede colegial (González Acuña, 2008, 96-98; 2011a, 173-177). nos así como de distintas corporaciones que confirman la singularidad e importancia adquirida por el puerto hispalense (González Fernández, 1993, 130 y ss.; 2017). En este contexto los datos económicos sintetizan los grandes cambios que se producen en este proceso de ascensión del emporio hispalense; establecimiento de figlinae, cetariae, volumen de productos comercializados así como la instalación y desarrollo de importantes áreas portuarias. Tal importancia del puerto de Hispalis, como puerto redistribuidor de mercancías hacia el interior de la provincia y como exportador de los productos de la misma hacia otras rutas y puertos mediterráneos incluido Portus y la propia Roma, le hará ganar en centralidad frente a ciudades históricamente más potentes como Gades o Corduba (Guzmán Armario, 2015, 48). El Betis, el cual da nombre a la provincia, se hacía así subsidiario del mar, siendo referencia para ambos la Colonia Romula Hispalis (Sevilla) que habría de representar respecto a la política marítima occidental desarrollada por $\mathrm{Au}-$ gusto lo mismo que Alejandría significaba para la oriental (Chic García, 2017, 842).

Al igual que en la ciudad gaditana, la llegada de Roma será un punto de inflexión en el sistema productivo-comercial hispalense. En época republicana las importaciones provenientes de la Bahía se limitarán a las salazones y salsamenta, evidenciándose una adopción del sistema romano en el repertorio anfórico -Dressel 7/11 e introducción masiva de T.S.I. y sus imitaciones locales-. No será hasta mediados del I a.C. cuando los artículos cerámicos del Valle del Guadalquivir empiecen a cobrar fuer$\mathrm{za}$, hasta entonces los productos de la costa superaban a los de la región por 3 a 1 (García Vargas, 2007 , 350; García y García, 2009, 161-162).

Será con el cambio de Era cuando Hispalis asuma el papel de puerto predominante bético, multiplicando por cuatro la producción olearia y vinaria respaldada por una potente producción anfórica que pudiera asumir el transporte de dichas mercancías. La eclosión de la economía olearia bética producida tras Tiberio fue vital, la demanda de la Urbs y las legiones fronterizas provocaron la necesidad de acondicionar el Baetis para instalar las nuevas infraestructuras de carga y descarga de mercancías (Chic García, 1988; 1990; 1998; García Vargas, 2003). En el puerto hispalense, salvo un $15 \%$ destinado al comercio regional, el resto estaba monopolizado por las mercancías y rutas oficiales. Los "concesionarios" al servicio de la administra- 


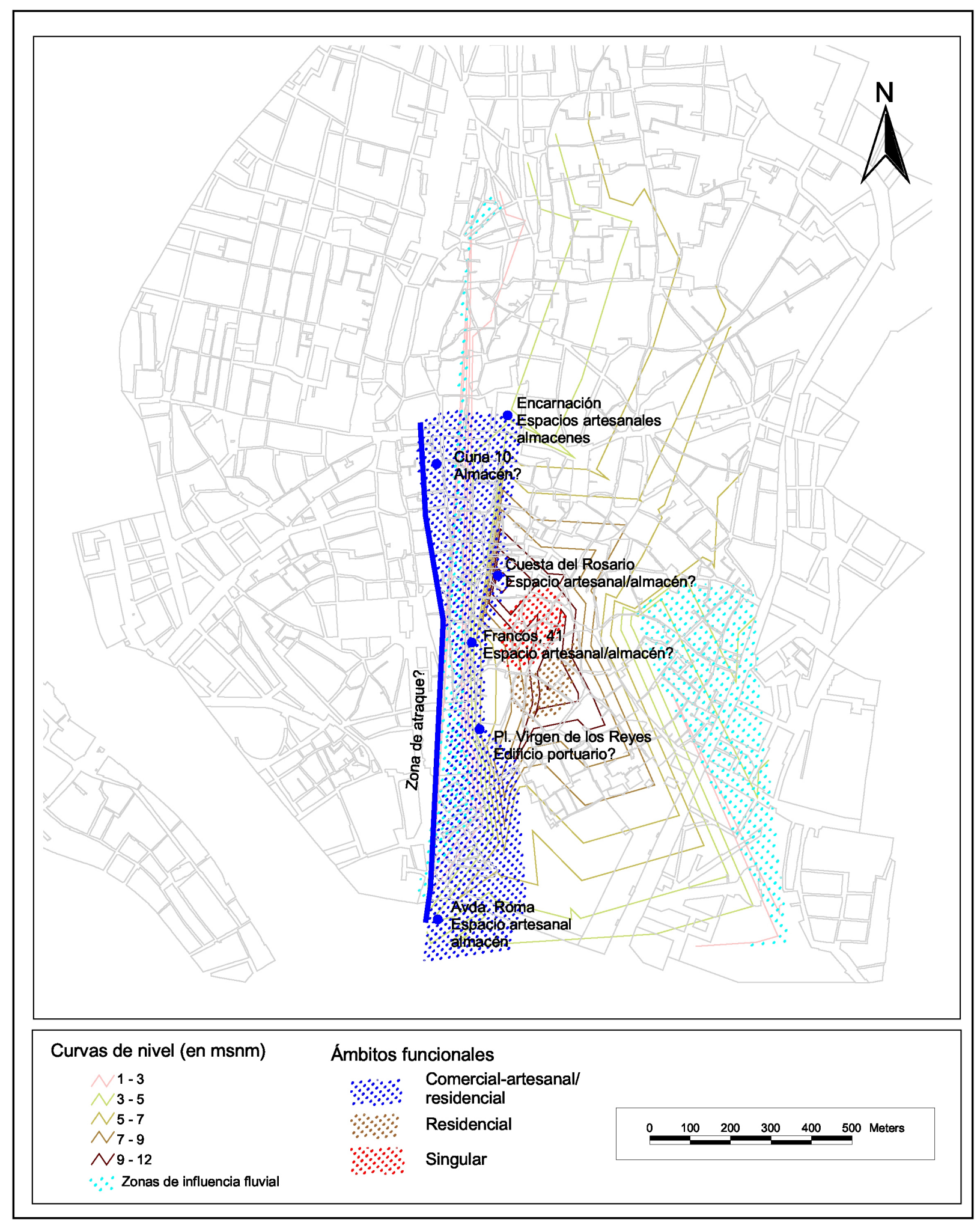

Fig. 4. Ámbitos funcionales de la ciudad de Hispalis en la 1a mitad del I d.C. (González Acuña, 2008, Fig. 13; 2011a, Fig. VIII.18) 
ción imperial utilizaban su posición para sus negocios, cargando salazones y vino para satisfacer la demanda de las élites urbanas, lo que benefició a $G a$ des, permitiendo ligar sus productos con las rutas annonarias (García Vargas, 2007, 351-353).

Durante la etapa flavia en la capital hispalense se advierte una creciente sistematización en las infraestructuras de carga y descarga de mercancías, evidenciando un aumento del tráfico comercial. Tanto en la zona sur de la ribera como en la norte se documenta una reorganización urbanística, una colmatación de los espacios libres y la monumentalización de éstos mediante la construcción de estructuras cultuales; además de una ampliación del perímetro amurallado (González Acuña, 2010, 104105; Ordoñez y González, 2011, 61-66). A finales de época flavia o antonina temprana se produce una gran reestructuración urbana (Fig. 5), se colmatan las piletas de salazones de la actual Encarnación; en la plaza de San Francisco se identifican posibles muelles y embarcaderos, atraques y construcciones de producción y almacenamiento en la orilla izquierda del Guadalquivir y tareas de mejora y acondicionamiento de los márgenes fluviales (González Acuña, 2010, 87-92).

La zona portuaria-comercial del sur de la ciudad entre el Tagarete y el Guadalquivir presenta una reforma sustancial, construyéndose calzadas e infraestructuras de saneamiento y reformando algunos edificios preexistentes. Estos elementos y otros como el mosaico dedicado a Mercurio Augusto encontrado en esta zona, unido al ya mencionado iseum y la posible statio olearium, ponen de relieve su carácter comercial-portuario. Las reformas asociadas a la posible sede de la statio fechadas en época adrianea así como su material epigráfico, confirma la continuidad de estas actividades durante el siglo II (González Acuña, 2010, 92-103). Esta reorganización de los espacios portuarios de Hispalis no significa que la ciudad perdiera su importancia comercial, de hecho la mantuvo hasta mediados del II cuando el aceite bético empieza a ser desplazado por el africano, en este sentido, el registro material de la Encarnación muestra un rico repertorio vinculado a una aristocracia urbana procedente de múltiples partes del imperio, especialmente de África y el Mediterráneo oriental (Ordoñez y González, 2011, 68-78).

El intervencionismo estatal en la annona a finales del I d.C. para controlar la intensificación de las explotaciones derivadas de la concesión del derecho latino a la comunidad hispana por parte de Vespasiano, provocaron la polarización de las actividades portuarias hacia la gestión del comercio del aceite en los dos puntos de la ciudad ya comentados. A pesar de su especialización funcional, a comienzos del II d.C. se observa una amortización de los espacios, tomando como ejemplo la actual plaza de la Encarnación, donde se construye un sector dedicado al uso doméstico ocupado por grandes domus (González Acuña, 2012, 872-874) y desplazando el punto focal del comercio oleario y sus corporaciones auxiliares a c/ Francos y Placentines, presentando un intenso tráfico comercial entre el IV y el V (González Acuña, 2010, 105).

A partir de la segunda mitad del II y durante el III se detecta una concentración de la ocupación en torno al núcleo urbano original, abandonándose los lujosos enclaves domésticos periurbanos y produciéndose la reorganización de la actividad portuaria en el eje de la actual c/ Sierpes-Alcázar (González Acuña, 2012, 874).

El PUERTO ANNONARIO DE HisPALIS Y EL FLORECIMiento del VALLE del Guadalquivir.

Inevitablemente, el Baetis como elemento articulador y dinamizador de la provincia que lleva su nombre es una de las causas principales del despegue económico del puerto hispalense, no solo por servir de conector entre las cabezas conventuales, sino por la riqueza agrícola que genera su cuenca hidrográfica, propiciando el nacimiento de multitud de centros productores de artículos complementarios como los contenedores cerámicos o la proliferación de industrias salazoneras, puertos y embarcaderos auxiliares. Estas circunstancias derivaron en la ampliación de los cultivos y campos de silos existentes en la zona, a los cuales se añadieron construcciones con funciones administrativas para el control de la annona (vid. Lacort Navarro, 1982;1985), así como en el establecimiento de todo un sistema viario organizado en torno al Guadalquivir y sus afluentes ${ }^{4}$.

4 La necesidad de adecuación y mantenimiento de los cauces fluviales obligó a llevar a cabo constantes tareas de preservación y control de esta navegación interior, primando los ríos principales como el Guadalquivir, Genil, Guadalete y Guadiamar, permitiendo fijar sus cursos y regular sus caudales para permitir el acceso a embarcaciones de pequeño calado mediante la construcción de diques y presas (sobre la navegación por el Guadalquivir y los puertos y estructuras que se distribuían por su cauce vid. Melchor Gil, 2002). Unas estructuras que estarían bajo la supervisión del procurator ad ripam Baetis en el caso del Guadalquivir, constatado en 


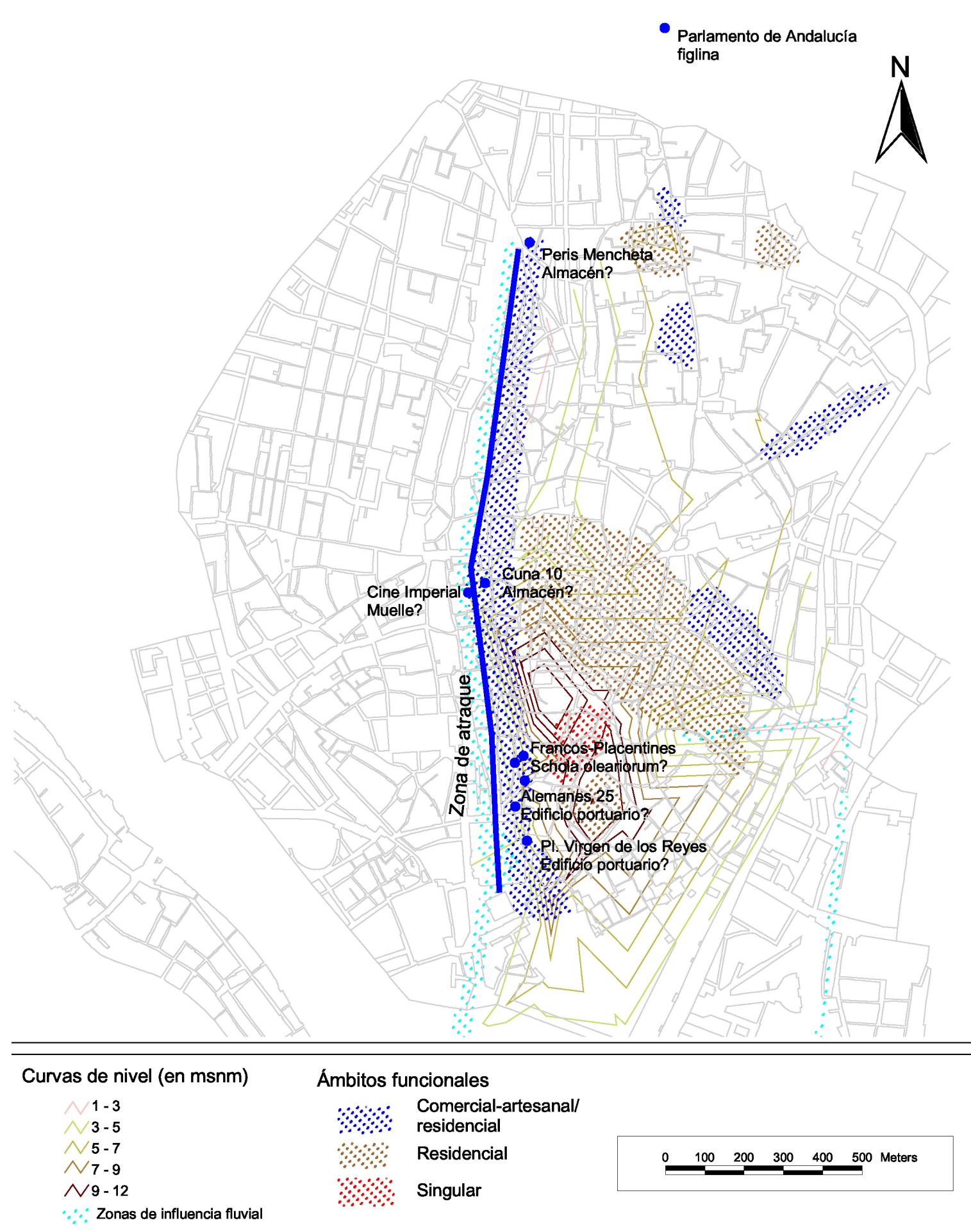

Fig. 5. Ámbitos funcionales de Hispalis en la primera mitad del II d.C. (González Acuña, 2008, Fig. 14; 2011a, Fig. VIII.20). 
La instauración de este sistema de caminos vino acompañada de la parcelación y ordenación del territorio ya desde época cesariana permitiendo el control de los recursos disponibles como se apuntaba inicialmente, de este modo el puerto sevillano se convirtió en el principal puerto bético en detrimento del gaditano (Chic García, 1997, 41-59; 2017 , 849; Guzmán Armario, 2015, 48).

El surgimiento de Hispalis como puerto principal en el desarrollo de estas políticas estatales produjo un importante desarrollo de las áreas circundantes interiores béticas, ahí reside quizás uno de los factores más importantes y que otorgarán a la ciudad y su puerto el ya mencionado papel de epicentro comercial y receptor de productos agrícolas. En este contexto el resto de capitales conventuales destacan desde fechas tempranas como sede de gobernadores y centro de control del territorio en las conexiones con la Citerior - Corduba-; por ser la escala portuaria de referencia en el Atlántico desde la etapa fenicia -Gades-; o por ser cabeza de un importante territorio con un alto potencial agrícola dirigido desde una ciudad -Astigi- con acceso directo a las vías fluviales que vertebran la provincia.

La expansión del modelo de vida romano basado en la ciudad incrementó el consumo y, consecuentemente, el tráfico comercial de la Provincia. La inserción de colonos en la Baetica, unida a la ampliación de los terrenos cultivables y a un sustrato indígena con una buena capacidad económica, será el contexto propicio para el florecimiento de una potencia exportadora que desplazará a los productos de origen griego e itálico, hasta que sean relevados por las producciones africanas. Todo ello unido a la necesidad de abastecer a una ciudad en constante crecimiento como Roma, así como a un numeroso ejército en campaña, obligaba a plantear unos sistemas productivos eficientes, dejando a un lado la agricultura de autoabastecimiento; estas son las claves que explican el ascenso de Hispalis como puerto principal bético en el transcurso del alto y medio imperio. Así pasa a convertirse en sede de un elevado número de procuratelas que evidenciaban su control sobre la producción agrícola y minera regional, así como su categoría como puerto principal de embarque para el transporte marítimo de la Bética. De este modo se generaba una dualidad

Hispalis en el siglo II (CIL II, 1180), del mismo modo que a partir de época flavia el mantenimiento de ríos y canales era responsabilidad de la ciudad así como las vías y calzadas -curatores viarum- (Chic García, 1997, 50-58). entre la sede del procónsul -Colonia Patricia- y la del procurator provinciae-Hispalis-, donde se emplazarían la administración y las infraestructuras annonarias (Caballos Rufino, 2016, 174-175).

Este aumento comercial bético, en donde el puerto de Hispalis supone el puerto exportador de un gran volumen de mercancías provinciales, se comprueba en que las ánforas olearias béticas se distribuyeran por todo el imperio, identificándose en época de Augusto más del 50\% del registro anfórico encontrado en las cuencas del Ródano-Rin, del mismo modo la conquista de Britania conllevó el aumento de la demanda de productos béticos -y lusitanos- para el abastecimiento de las tropas. En esta etapa, Claudio facilitó el transporte de mercancías para aquellos comerciantes que sirvieran al Estado con el tráfico annonario, asegurándoles unas ganancias mínimas así como una serie de privilegios fiscales y jurídicos como el ius quiritum para los latinos que colaborasen, tratando de captar a la élite que ansiaba adquirir la plenitud de derechos. Estas medidas supusieron un aumento de la producción y el comercio teniendo su reflejo en el número de senadores béticos durante el reinado de Claudio (Chic García, 1995, 74-84; Remesal Rodríguez, 2004; González Fernández, 2017).

Tras la muerte de Nerón el sistema se fiscaliza más, gravando a las élites y obligándolas a asumir los cargos públicos y sus correspondientes gastos, con Adriano las minas del suroeste alcanzan sus cotas más elevadas de producción gracias al potente intervencionismo estatal, dando muestras de una situación preocupante en el Imperio que se corrobora con el descenso de dedicatorias privadas al culto imperial y de representantes hispanos en el Senado en beneficio de los orientales, constatando el declive de la cuenca hidrográfica del Guadalquivir (Chic García, 2005, 61-62).

El intervencionismo progresivo que se fue instaurando en la economía desde la construcción del puerto de Trajano repercutió en el tráfico annonario, lo que debió suponer una relación cada vez más formalizada entre los collegia navicularii, negotiatores y mercatores con la administración pública (García Vargas, 1998; García y Martínez, 2009). La misma que desde finales del siglo primero reduce la dependencia de las compañías arrendatarias a la vez que promocionaba a los colegios profesionales como instancias encargadas de la gestión y transporte de los géneros fiscales. Esta reestructuración es visible en el abandono de amplias zonas artesa- 
nales y portuarias a fines del I y principios del II y el tráfico de determinadas mercancías de interés para el Estado. A partir del s. II en Roma se observa un incremento de epigrafía de corporaciones olerías béticas contando en Sevilla con una sede importante -statio olearium - a mediados del II o principios del III tras la contracción del área portuaria (García Vargas, 2012a, 261-262). Las dinámicas centralizadoras estatales llevarán a la progresiva expulsión de los productos gaditanos de las rutas oficiales; en Roma se pasa de un 30'6\% de ánforas gaditanas a principios del I d.C., 12'8\% a mediados y alrededor del $5 \%$ a final de siglo, aunque se documenta una gran exportación a Britania y Campania por las necesidades militares pero fuera de los circuitos habituales. Por su parte los mercados italianos reciben ánforas béticas de salazones pero sin pasar por Ostia, evidenciando este cambio en las rutas comerciales (García Vargas, 1998, 222-232).

En síntesis, la apuesta de César, como arquitecto, y de Augusto, como ejecutor, por la dinamización de la cuenca del Guadalquivir como uno de los grandes "graneros" de Roma, supuso que a comienzos del siglo I de nuestra Era, Hispalis fuera el centro neurálgico de toda esta política económica, sus especiales condiciones geográficas y fluvio-marítimas le concedían toda una serie de ventajas frente al tradicional puerto gaditano lo que cristalizará en el papel protagonista durante todo el altoimperio del puerto hispalense.

\section{BiBLIOGRAFÍA}

Abascal Palazón, J.M. (2006), "Los tres viajes de Augusto a Hispania y su relación con la promoción jurídica de ciudades”, Iberia, 9, 63-78.

Arteaga, O., Kölling, A, Kölling, M., Roos, A.M., Schulz, H. y Schulz, H.D.

(2001), "El puerto de Gadir. Investigación geoarqueológica en el casco antiguo de Cádiz", RAMPAS, 4, 345-415.

(2004), "Geoarqueología Urbana de Cádiz. Informe preliminar sobre la campaña de 2001", $A A A$ 2001, III.1, 27-40.

Beltrán, J., González, D. y Ordóñez, S. (2005), "Acerca del urbanismo de Hispalis. Estado de la cuestión y perspectivas”, Mainake, XXVII, 61-88.

Bernal Casasola, D. (2008), “Gades y su bahía en la Antigüedad. Reflexiones geoarqueológicas y asignaturas pendientes”, RAMPAS, 10, 267308.
(2012), "El puerto romano de Gades. Novedades arqueológicas", Rome, Portus and the Mediterranean (Keay, S. Ed.), Londres, 225-244.

Bernal, D. y Arévalo, A. (Eds.) (2011), El Theatrum Balbi de Gades, Cádiz.

Bernal, D. y Lagóstena, L.G. (2004), “Alfares y producciones cerámicas en la provincia de Cádiz. Balance y perspectivas", Figlinae Baetica: talleres alfareros y producciones cerámicas en la Bética romana (ss. II a.C.-VII d.C.) (Lagóstena, L.G. y Bernal, D. Eds.), Vol. 1, Cádiz, 39-124.

Bernal, D. y Lara, M. (2012), "Desenterrando a $G a$ des. Hitos de la arqueología preventiva, mirando al futuro", Hispaniae Vrbes. Investigaciones arqueológicas en ciudades históricas (Beltrán, J. y Rodríguez, O. Coords.), Sevilla, 423-473.

Blanco Freijeiro, A. (1979), La ciudad antigua (De la prehistoria a los visigodos), Sevilla.

(1992), "La Sevilla Antigua", Historia de Sevilla (Morales Padrón, F. Coord.), Sevilla, 19-92.

Caballos Rufino, A. (2016), "Las «ciudades del poder» en la Bética”, Revista de Historiografía, 25, 157-176.

Cabrera Tejedor, C. (2014), "La caracterización del antiguo y desaparecido puerto de Sevilla a través de los hallazgos náuticos de la Plaza Nueva”, Sevilla Arqueológica: La ciudad en época protohistórica, antigua y andalusí (Beltrán Fortes, J. y Rodríguez Gutiérrez, O. Eds.), Sevilla, 242-244.

(2016), From Hispalis to Ishbiliyya: the ancient port of Seville, from the Roman Empire to the end of the Islamic period (45 BC - AD 1248), tesis doctoral inédita, Universidad de Oxford.

Campos Carrasco, J.M.(1986), Excavaciones arqueológicas en la ciudad de Sevilla. El origen prerromano y la Hispalis romana, Sevilla. (1990), "Estructura urbana de la Colonia Iulia Romula Hispalis en época republicana”, Habis, 20, 245-262.

(1993), "La estructura urbana de la Colonia Iulia Romula Hispalis en época imperial", $A A C, 4$, 181-219.

Campos, J.M. y Bermejo, J. (2015), “Las medidas políticas y territoriales de Augusto en el extremo occidental de la Bética”, Augusto y la Bética. Aspectos históricos y arqueológicos (Márquez, C. y Melchor, E. Coords.), Córdoba, 195-215. 
Campos, J.M. y González, J. (1987), "Los foros de Hispalis Colonia Romula”, AEA, 60, 123-158.

Chaves, F., Melchor, E., Oria, M. y Gil, R. (1999), "Paisaje urbano en los siglos I a.C.- I d.C. y la emisión de la moneda local: el caso de Gades" Ciudades privilegiadas en el Occidente Romano: naturaleza y evolución, organización jurídica y modelos urbanos, Sevilla, 87-99.

Chic García, G. (1979), "Gades y la desembocadura del Guadalquivir”, Gades, 3, 7-23.

(1988), Epigrafía anfórica de la Bética II. Los rótulos pintados sobre ánforas oleárias. Consideraciones sobre la annona, Écija.

(1990), La navegación por el Guadalquivir entre Córdoba y Sevilla en época romana, Sevilla.

(1991), "Economía y Política en la Época de Tiberio. Su reflejo en la Bética”, Laverna, II, 76-128.

(1995), "Roma y el mar: del Mediterráneo al Atlántico”, Guerra, exploraciones y navegación: del Mundo Antiguo a la Edad Moderna (Alonso Troncoso, V Coord.), A Coruña, 55-89.

(1997), Historia económica de la Bética en la época de Augusto, Sevilla.

(1998), Breve historia económica de la Bética romana, Sevilla.

(2001), Datos para un estudio socioeconómico de la Bética, Sevilla.

(2005), "Marco Aurelio y Cómodo, el hundimiento de un sistema económico". Annaeus: anales de la tradición romanística, 2, 45-66.

(2010-2011), "El aceite y el vino de la Bética. Entre el prestigio y el mercado”, AnMurcia, 25-26, 279-295.

(2017): "Perspectivas económicas de la Bética de Augusto”. Gerión, Vol. 35, $n^{\circ}$ Esp. 839-861.

Collantes de Terán, F. (1977), Contribución al estudio de la topografía sevillana en la Antigüedad y en la Edad Media, Sevilla.

Díaz, J.J., Sáez, A.M., Toboso, E.J., Montero, A. y Montero, R. (2003), "Las producciones cerámicas en las bahías de Algeciras y Cádiz en la Antigüedad. Análisis comparativo de sus trayectorias alfareras", Almoraima, 29,123-137.

Etienne, R. (1974), Le culte imperial dans la Péninsule Iberique d'Auguste a Diocletien, $\mathrm{Pa}-$ rís.

Expósito Álvarez, J.A. (2004), Las factorías de salazón de gades (siglos II a.C. - VI d.C.). Estudio arqueológico y estado de la cuestión, Trabajo de Investigación de tercer Ciclo, Universidad de Cádiz.
Fornell Muñoz, A. (2015), "El Alto Guadalquivir en época augustea”, Augusto y la Bética. Aspectos históricos y arqueológicos (Márquez, C. y Melchor, E. Coords.), Córdoba, 13-38.

García Vargas, E. (1998), La producción de ánforas en la bahía de Cádiz en época romana (siglos II a.C.-IV d.C.), Écija.

(2003), "La industria alfarera en el bajo Guadalquivir en época romana", Arqueología y rehabilitación en el Parlamento de Andalucía. Intervenciones arqueológicas en el Antiguo Hospital de las Cinco Llagas de Sevilla (Vázquez Labourdette, A., Coord.), Sevilla, 123-138.

(2004), "Las ánforas del vino bético altoimperial: formas, contenidos y alfares a la luz de algunas novedades arqueológicas", Actas del Congreso Internacional Figlinae Baeticae. Talleres alfareros y producciones cerámicas en la Bética romana (ss. II a.C. - VII d.C), Oxford, 507-514.

(2007), "Hispalis como centro de consumo desde época tardorrepublicana a la Antigüedad tardía. El testimonio de las ánforas”, $A A C, 18,317-360$.

(2010), "Ánforas béticas de época augusteo-tiberiana. Una retrospectiva”, Las necrópolis de Cádiz. Apuntes de arqueología gaditana en homenaje a J.F. Sibón Olano (Niveau, A.M. y Gómez, V. Coords.), Cádiz, 581-622.

(2012a), "Hispalis (Sevilla, España) y el comercio mediterráneo en el Alto Imperio Romano. El testimonio de las ánforas", Portus and the Mediterranean. Archaeological Monographs of The British School at Rome (Keay, S., Ed) Roma, 245-266

(2012b), "Aspectos socioeconómicos de la antigüedad tardía en la Bética (siglos III-VII d.C.)”, La arqueología romana de la provincia de Sevilla. Actualidad y perspectivas (Beltrán, J., Rodríguez de Guzmán, S. Coords.), Sevilla, 235253.

García, E. y Bernal, D. (2009), "Roma y la producción de garum y salsamenta en la costa meridional de Hispania. Estado actual de la investigación”, Arqueolgía de la pesca en el Estrecho de Gibraltar. De la prehistoria al fin del mundo antiguo (Bernal Casasola, Ed.), Cádiz, 133-181.

García, E. y Chaves, F. (1991), "Reflexiones en torno al área comercial de Gades. Estudio numismático y económico", Gerión, no extra 3, 139-168. García, E. y García, F.J. (2009), "Romanización y 
consumo: cambios y continuidades en los contextos cerámicos de Hispalis en épocas turdetana y romano-republicana”, Spal, 18, 131-165.

García, E. y Martínez, J. (2009), "Fuentes de riqueza y promoción social de los negotiantes salsarii béticos durante el alto imperio romano. Una aproximación diacrónica”, AEspA, 82, 133-52.

García, E., Ordóñez, S. y Cabrera, C. (2017), "El puerto romano de Hispalis. Panorama arqueológico actual”, Los puertos Atlánticos Béticos y Lusitanos y su relación comercial con el Mediterráneo (Campos, J.M. y Bermejo, J. eds.), Roma, 245-286.

Gener, J.M. y Pajuelo, J.M. (2002), "El Cádiz romano", Cádiz al fin del milenio. Cinco años de arqueología en la ciudad (1995-2000). Catálogo de la Exposición, Sanlúcar de Barrameda, 41-46.

González Acuña, D. (2010), "Hispalis, puerto romano de la Bética. Aproximación urbanística", Bollettino di Archeologia on line, Volume speciale, 83-111.

(2011a), Forma Urbis Hispalensis: El urbanismo de la ciudad romana de Hispalis a través de los testimonios arqueológicos, Sevilla.

(2011b), "La civilización del agua en la Hispalis romana”, Sevilla y el Agua (Collantes de Terán, A. Ed.), Sevilla, 13-35.

(2012), "Planificación y gestión urbana en Hispalis", Hispaniae Urbes. Investigaciones arqueológicas en ciudades históricas (Beltrán, J., Rodríguez, O. Coords.), Sevilla, 859-880.

González Fernández, J. (1993), "Hispalis Colonia Romula", Ciudad y comunidad cívica en Hispania: siglos II y III d. C., Madrid, 127-138

(2017), "La presencia de magistrados imperiales y subalternos en la epigrafía de Hispalis Colonia Romula", Los puertos atlánticos béticos y lusitanos y su relación comercial con el Mediterráneo (Campos, J.M. y Bermejo, J. Eds.), Roma, 287-305.

Gozalbes Cravioto, E. (1995): "Comercio y proyección económica de las ciudades de la Hispania meridional romana (siglos II a.C.- 1 a.C.)". Flor. $l l ., 6,229-243$.

Guzmán Armario, F.J. (2015), "La Bética en la geopolítica de Augusto”, Augusto y la Bética. Aspectos históricos y arqueológicos (Márquez, C. y Melchor, E. Coords.), Córdoba, 41-57.

Lacort Navarro, P. (1982): "Sobre las construcciones romanas del Carchena (término municipal de Castro del Río, Córdoba”, Habis, 13, 171-188.

(1985): "Cereales en Hispania Ulterior: silos de época ibero-romana en la Campiña de Córdoba”, Habis, 16, 363-386.

Lapeña Marchena, O. (1996), "El anfiteatro gaditano en la historiografía local de los siglos XVI y XVII", Anales de la Universidad de Cádiz, 1, 123-135.

Lara Medina, M. (2017), Urbs Iulia Gaditana. El urbanismo de Gades a través del registro arqueológico. Análisis y propuesta interpretativa, tesis doctoral, inédita, Universidad de Cádiz.

Lechuga, M.A., Bellón, J.P. y Rueda, C. (2015), "Iliturgi: conflicto culto y religioso (s. III a.C. s. I d.C.)", Augusto y la Bética. Aspectos históricos y arqueológicos (Márquez, C. y Melchor, E. Coords.), Córdoba, 59-88.

Melchor Gil, E. (2002), "La navegación por el Guadalquivir en época Antigua y Medieval", Patrimonio Histórico Hidráulico de la Cuenca del Guadalquivir, Madrid, 319-347

(2014), "El patronato sobre comunidades cívicas hispanas en época augustea”. Stud. hist., H. ${ }^{a}$ antig., 32, 249-279.

Montero, A.I., Montero, R., Sáez, M. y Díaz, J.J. (2004), "Innovaciones, transformaciones y pervivencias. Evolución de la alfarería gadirita durante los ss. III-II a.n.e.”, FIGLINAE BAETICAE. Talleres alfareros y producciones cerámicas en la Bética romana (ss. II a.C. - VII d.C.), Oxford, 413-426.

Niveau de Villedary, A.M. (2014), "De colonia a ciudad. Algunos apuntes sobre la situación y naturaleza de la ciudad de Gadir", Treballs del Museu Arqueologic d'Eivissa e Formentera, 72, 485-501.

(2015), "La estructuración del espacio urbano y productivo de Gadir durante la Fase Urbana Clásica: cambios y perduraciones". Complutum, Vol. 26 (1), 225-242.

Niveau, A.M. y Ruiz, D. (2000), “El poblado de Las Cumbres (Castillo de Doña Blanca): Urbanismo y materiales del s. III a.n.e.”, IV Congreso Internacional de Estudios Fenicios y Púnicos, Vol. II, 893-903.

Ordóñez, S. y González, D. (2011), “Colonia Romula Hispalis. Líneas esenciales de su dinámica histórica y arqueológica”, Colonias de César y Augusto en la Andalucía romana (González, J., Saquete, J.C. Eds.), Sevilla, 47-98. 
Oscáriz Gil, P. (2009), “Organización administrativa y territorial de las provincias hispanas durante el Alto Imperio", Hispaniae. Las provincias hispanas en el mundo romano (Cabrero, J., Pintado, J.A. y Rodà, I. Eds.), Tarragona, 323-338.

Pastor Muñoz, M. (2015), "las ciudades de bastetania en época de Augusto”, Augusto y la Bética. Aspectos históricos y arqueológicos (Márquez, C. y Melchor, E. Coords.), Córdoba, 103-146.

Perdigones, L., Muñoz, A. y Pisano, G. (1990), "La necrópolis fenicio-púnica de Cádiz. Siglos VI al IV a.C.”, Studio Punica, 7, Roma.

Pérez Macías, J.A. (2002), "Metalla y territoria en el oeste de la Baetica", Habis, 33, 407-431.

Plácido Suárez, D. (1987-1988), "Estrabón III: El territorio hispano, la geografía griega y el imperialismo romano", Habis, 18-19, 243-256.

Ponsich, M. (1968), “Alfarerías de época fenicia y púnico-mauritana en Kuass (Arcila, Marruecos)", Papeles del laboratorio de arqueología de Valencia, Vol. 4, 3-25.

Remesal Rodríguez, J. (2004), "Promoción social en el mundo romano a través del comercio", Actas de la reunión Vivir en tierra extraña: emigración e integración cultural en el mundo antiguo (Remesal, J., Marco, F. y Pina, F. Coords.), Zaragoza, 125-136.

Rodríguez Temiño, I. (1991), “Algunas cuestiones sobre el urbanismo de Hispalis en época republicana”, Habis, 22, 157-175.

Ruiz Mata, D. (1986), "Castillo de Doña Blanca (Puerto de Santa María, prov. Cádiz). Stratigraphische Untersuchung einer orientalisierenden Andsiedlung”, Madrider Mitterlungen, 27, 87-115.

(1987), "La formación de la cultura turdetana en la Bahía de Cádiz a través del Castillo de Doña Blanca”, Iberos. Actas de las I Jornadas sobre el Mundo Ibérico, 299-314.

Ruiz, D. y Pérez, C.J. (1995), El poblado fenicio del Castillo de Doña Blanca (El Puerto de Santa María, Cádiz), Cádiz.

Sáez Romeo, A.M. (2008), "El sistema alfarerosalazonero de Gadir/Gades”, Saguntum, 40, 141-160.

(2010), "La producción alfarera y la economía salazonera de gadir: balance y novedades", Mainake, XXXII (II), 885-932.

Sáez, A.M. y Díaz, J.J. (2012), "Entre tierra y mar, entre lo púnico y lo romano. Adaptaciones económicas y territoriales en un medio cambiante: algunas notas sobre paleografía y sistemas de explotación del hinterland insular de Gadir/ Gades”, La etapa neopúnica en Hispania y el Mediterráneo centro occidental: identidades compartidas (Mora, B. y Cruz, G., Coords.), Sevilla, 259-299.

Sáez, A.M., Belizón, R. y Carrero, F. (2017), “Primeras evidencias de un nuevo yacimiento púnico y romano en San Fernando (Cádiz)". Boletín Ex Officina Hispana 8, 12-16

(2014), "El alfar gaditano de El Palomar (El Puerto de Santa María, Cádiz). Aportaciones a su secuencia de actividad y sus producciones”. As produções cerâmicas de imitação na Hispania, monografias ex officina hispana II (Morais, R., Fernández, A. y Sousa, M.J., Eds.), Madrid, 179-197.

Sáez, P., Ordoñez, S., García, E. y García-Dils, S. (2004), "Carta Arqueológica Municipal de Écija (Sevilla)", Ciudad y territorio. Las Cartas Arqueológicas. VIII Jornadas de Arqueología Andaluza, Sevilla.

Tabales Rodríguez, M.A. (2001), “Algunas aportaciones arqueológicas para el conocimiento urbano de Hispalis", Habis, 32, 387-423.

Ureña Alonso, J. (2001), "Los conventus de la Provincia Baetica a partir de la descripción geográfica de Ptolomeo", Habis, 42, 209-27.

Ventura Villanueva, A. (2008), "Gadir-Gades", Arte Romano de la Bética I. Arquitectura y urbanismo (León Alonso, P. ed.), Sevilla, 7681.

Villaverde Vega, N. (1997), "Sobre la decadencia económica y urbana de Gades en el contexto político del siglo III", Espacio. Tiempo y Forma. Serie II. Historia Antigua, t. 10, 403-414.

Wulff, F. (1996), "La acción colonizadora de Augusto en la Bética”, Revisiones de Historia Antigua II. Teoría y práctica del ordenamiento municipal en Hispania, Vitoria, 41-52. 